Solution processed copper tetrabenzotriazaporphyrin films for organic field effect transistors

Nandu B. Chaure, Andrew N. Cammidge, Isabelle Chambrier, and Asim K. Ray

Citation: Journal of Applied Physics 124, 235501 (2018); doi: 10.1063/1.5055588

View online: https://doi.org/10.1063/1.5055588

View Table of Contents: http://aip.scitation.org/toc/jap/124/23

Published by the American Institute of Physics

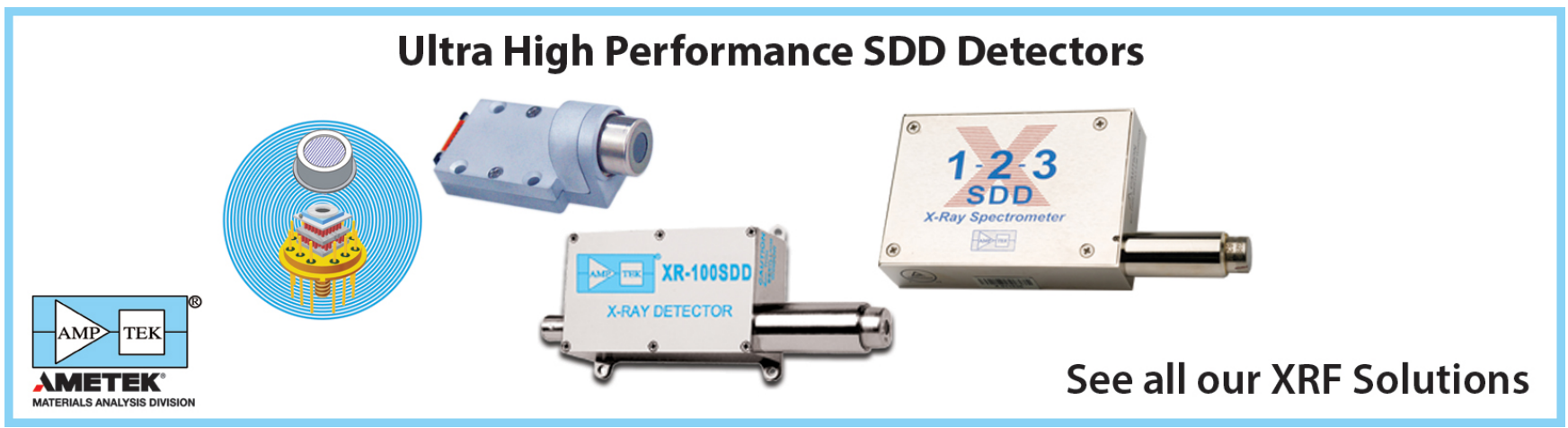




\title{
Solution processed copper tetrabenzotriazaporphyrin films for organic field effect transistors
}

\author{
Nandu B. Chaure, ${ }^{1}$ Andrew N. Cammidge ${ }^{2}$ Isabelle Chambrier, ${ }^{2}$ and Asim K. Ray ${ }^{3}$ \\ ${ }^{1}$ Department of Physics, Savitribai Phule Pune University, Pune 411007, India \\ ${ }^{2}$ School of Chemistry, University of East Anglia, Norwich NR4 7TJ, United Kingdom \\ ${ }^{3}$ Department of Electronic and Computer Engineering, Brunel University London, Uxbridge UB8 3PH, \\ United Kingdom
}

(Received 8 September 2018; accepted 29 November 2018; published online 17 December 2018)

\begin{abstract}
Experimental characteristics of bottom-gate-contact organic thin film field-effect transistors (OTFTs) with $70 \mathrm{~nm}$ thick films of solution processed non-peripherally octahexyl-substituted copper tetrabenzotriazaporphyrin (6CuTBTAP) novel asymmetric molecules as active layers on silicon substrates are analyzed by both linear and non-linear parameter extraction methods in order to examine the fielddependent mobility and contact effects. Both linear and saturation field effect mobilities of OTFTs have been computationally determined as a function of gate voltage in the presence of the contact resistances. The Poole-Frankel mechanism is found to be responsible for charge transport during the saturation regime, giving the highest mobility of $6.9 \times 10^{-2} \mathrm{~cm}^{2} \mathrm{~V}^{-1} \mathrm{~s}^{-1}$ at the gate-source voltage $\left(\mathrm{V}_{\mathrm{G}}\right)$ of $50 \mathrm{~V}$. The on-off ratio is found to be $10^{6}$. The contact resistance at the interface between gold electrodes and the 6CuTBTAP active layer decreases with $\mathrm{V}_{\mathrm{G}}$ sharply from $75 \mathrm{M} \Omega$ corresponding to $\mathrm{V}_{\mathrm{G}}=0 \mathrm{~V}$ to $10 \mathrm{M} \Omega$ once the transistor is turned on at the threshold voltage. Published by AIP Publishing. https://doi.org/10.1063/1.5055588
\end{abstract}

\section{INTRODUCTION}

Tetrabenzotriazaporphyrins (TBTAPs) are macrocyclic semiconductors structurally related to well-investigated organic phthalocyanine $(\mathrm{Pc})$ compounds and show interesting physical properties with the potential for applications in electro-optic devices for optical data storage, solar cells, field-effect transistors, electrochemical transistors, displays, and non-phototoxic dendritic nanoprobes for tissue oxygen measurements. ${ }^{1,2}$ The TBTAPs differ from Pcs in which one of the four bridging nitrogen atoms in the latter is replaced by an $\mathrm{sp}^{2}$ hybridized carbon atom. ${ }^{3}$ However, the chemical synthesis of TBTAP compounds is far more challenging than for phthalocyanines. The lower symmetry TBTAP ring system has, until recently, been far less readily available than phthalocyanines. ${ }^{4}$ Four-probe conductivity measurements on doped copper tetrabenzotriazaporphyrin (CuTBTAP) at $27 \mathrm{~Hz}$ showed a conductivity of $100-500 \mathrm{Scm}^{-1}$ at ambient temperatures that increased on cooling to ca. $90 \mathrm{~K}$ and then decreased on further cooling to $5 \mathrm{~K}$. A similar pattern of temperature dependence was observed when the measurements were repeated at $13 \mathrm{GHz}$, implying that the intrinsic charge transport is not influenced by the contacts. ${ }^{5}$ Microwave conductivity measurements on $\mathrm{Cu}$ metallated TBTAP at temperatures varying between $2 \mathrm{~K}$ and $300 \mathrm{~K}$ at $13 \mathrm{GHz}$ show the decrease from the room temperature metallic of $3 \times 10^{2} \mathrm{Scm}^{-1}$ to $7 \times 10^{2} \mathrm{Scm}^{-1}$ for the low temperature varying between $10 \mathrm{~K}$ and $40 \mathrm{~K}$. Magnetic moments localised on the $\mathrm{Cu}+$ metal spine in this quasi-one-dimensional conductor is believed to be responsible for this behavior. ${ }^{6,7}$ The electrical conduction of both $\mathrm{Cu}$ and $\mathrm{Ni}$ metallated TBTAP after oxidative doping using iodine has been investigated over the temperature range between $100 \mathrm{~K}$ and $300 \mathrm{~K}$, and then a comparison of the results with correspondingly doped phthalocyanines indicates the 12 orders of magnitude increase in the conductivity along the needle (crystallographic a) axis. The oxidation from both ligand $\pi$-orbitals and metal d-orbitals has been identified from the electron paramagnetic resonance spectra, displaying doubly mixed-valence states. ${ }^{8,9}$ Electrochemical oxidation of copper and nickel triazatetrabenzoporphyrinato $\left([\mathrm{CuTBTAP}]_{3}\left[\mathrm{ReO}_{4}\right]_{2} \cdot \mathrm{C}_{10} \mathrm{H}_{7} \mathrm{Cl}\right.$ and [NiTBTAP $]_{3}\left[\mathrm{ReO}_{4}\right]_{2} \cdot \mathrm{C}_{10} \mathrm{H}_{7} \mathrm{Cl}$ ) dissolved in 1-chloronaphthalene in the presence of the perrhenate ion provided access to partially ligand oxidised crystals of both complexes, forming trimerised stacks responsible for their semiconducting behavior of the range between $0.25 \times 10^{-4} \mathrm{Sm}^{-1}$ and $0.3 \mathrm{Sm}^{-1}$ and an activation energy for conduction in the range of $0.24-0.26 \mathrm{eV} .^{10}$

Following these early works, several attempts have been made in recent years to improve the synthesis of solution processable asymmetric TBTAP macrocyclic compounds with a view to realising their potential large-scale device applications. The mesophase properties of the new derivatives are very interesting for device applications. ${ }^{11}$ For example, theoretical investigations into optical properties of solution processed TBTAP molecules show the presence of HOMO and LUMO at $-4.44 \mathrm{eV}$ and $-2.47 \mathrm{eV}$, giving the value of 1.97 $\mathrm{eV}$ for the bandgap. The carrier mobility is estimated to be $1.06 \mathrm{~cm}^{2} \mathrm{~V}^{-1} \mathrm{~s}^{-1}$. ${ }^{12}$ A value of $0.028 \mathrm{eV}$ is obtained for the activation energy from four-probe conductivity measurements between $83 \mathrm{~K}$ and $250 \mathrm{~K}$ on axially substituted iron (FeTBTAP). This value is found to be higher than its phthalocyanine analogs. This semiconducting superior behavior of FeTBTAP is attributed to the reduction in intermolecular $\pi-\pi$ overlapping possibly due to its distances and angles between pyrroles and atoms at the meso positions larger as revealed by X-Ray diffraction studies on the crystal structures. ${ }^{13}$ Solution-processed thin films of 5,15-bis(triisopropylsilyl) 
ethynyltetrabenzoporphyrin is found to form a brick work packing of two dimensionally extended $\pi$-staking. The field-effect hole mobility is $1.1 \mathrm{~cm}^{2} \mathrm{~V}^{-1} \mathrm{~s}^{-1}$, a value 14 times greater than its unsubstituted compounds. ${ }^{14}$ The room temperature characteristics of the bottom gate configured Organic field effect transistors (OFETs) employing approximately $70 \mathrm{~nm}$ thick spin-coated films of non-peripherally octahexyl substituted nickel tetrabenzotriazaporphyrin (6NiTBTAP) molecules exhibit performance superior to their phthalocyanine analogs in terms of high mobility, low threshold voltage, large on/off current ratio, and steeper sub-threshold slope. Compactly packed long fibers observed in the 6NiTBTAP film are believed to be responsible for enhanced in-plane charge transport in the channel between the drain and the source. ${ }^{15}$ Values of the carrier mobility and on-off ratio for similarly configured OFETs with octadecyl substituted copper tetrabenzotriazaporphyrin (10CuTBTAP) active layer are found from standard square law dependence of saturation current upon the gate-to-source voltage $\left(\mathrm{V}_{\mathrm{G}}\right)$ to be $5 \times 10^{-3} \mathrm{~cm}^{2} /$ Vs and $10^{4}$, respectively, and these values are nearly one order of magnitude higher than the phthalocyanine analog $(10 \mathrm{CuPc})$ layer transistor. Compact modeling, however, shows that the $10 \mathrm{CuPc}$ layer is relatively more susceptible to trapping degradation near the gate region than a 10CuTBTAP layer, which is significant in order to achieve stability in these transistors. ${ }^{16}$

This article presents the results of an experimental investigation into the characteristics of OFETs using $70 \mathrm{~nm}$ thick polycrystalline films of copper-1,4,8,11,15,18,22,25-octakis(hexyl) tetrabenzotriazaporphyrin (6CuTBTAP) as active semiconductor layers. The chemical structure of the molecule is shown in Fig. 1(a). Both linear and nonlinear extraction methods have been employed for analysis of the transistor parameters such as saturation mobility $\left(\mu_{\text {sat }}\right)$, threshold voltage $\left(V_{T}\right)$, sub-threshold voltage swing $(\mathrm{S})$, and on-off ratio. Emphasis is given on the morphology-dependent charge transport contributing to the effect of contact resistance between the source and drain gold electrodes. Molecular orbital calculations of the two ring systems indicate the similarities of 6TBTAP compounds with their Pc analogs but the 6TBTAP structure delivers a somewhat larger HOMO-LUMO energy difference of $1.77 \mathrm{eV}$, showing a small hypsochromic shift of the visible region adsorption band. ${ }^{17}$ 6CuTBTAP is chosen because it combines the intrinsic asymmetry unique to TBTAPs with hexyl chain substituents that impart both solution processability and self-organisation in the films for flexible electronics.

\section{EXPERIMENTAL}

Novel synthesis methods of non-peripherally octaalkylsubstituted derivatives of tetrabenzotriazaporphyrin have been developed in recent years by treating 3,6-dihexylphthalonitrile with $\mathrm{MeMgBr}$ and then separating the mixture of phthalocyanine/hybrids by chromatography. ${ }^{18}$ Treatment of the TBTAP with copper acetate gave the metallated derivative 6CuTBTAP. Employing a KW-4A two stage spin coater (Chemat Technology Inc.) initially at $1000 \mathrm{rpm}$ for $30 \mathrm{~s}$ and subsequently at 2000 rpm for $60-90 \mathrm{~s}, 70 \mathrm{~nm}$ thin and uniform film of 6CuTBTAP layers were deposited onto highly n-doped Si (110) wafer (a)

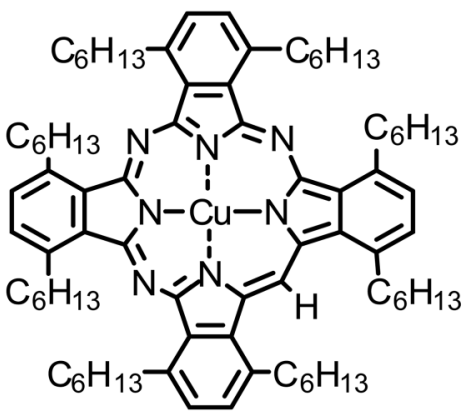

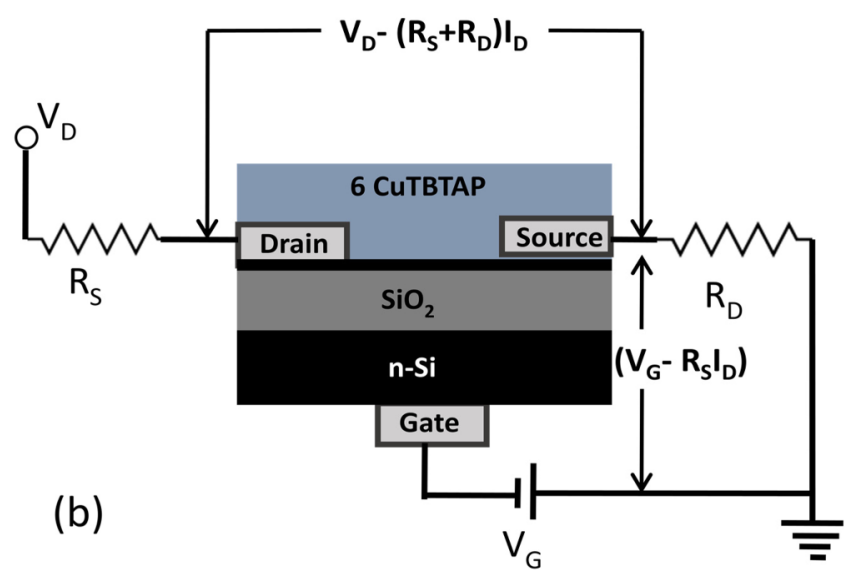

FIG. 1. (a) Chemical structure octahexyl substituted copper tetrabenzotriazaporphyrin (6CuTBTAP) with eight hexyl chains $\left(\mathrm{C}_{6} \mathrm{H}_{13}\right)$ on non-peripheral sites. (b) Bottom gate bottom contact OFET structure with channel length $\mathrm{L}=5 \mu \mathrm{m}$ and channel width $\mathrm{W}=2 \mathrm{~mm}$.

gates of resistivity 1 to $5 \Omega / \mathrm{cm}$ covered with $300 \mathrm{~nm}$ thick thermally grown oxide gate layer having a capacitance per unit area $C_{i}=9 \mathrm{nF} / \mathrm{cm}^{2}$, preventing current flow between the gate and source/drain contacts. Two finger shaped gold electrodes (Au coated Ti electrodes; $\mathrm{Au}=50 \mathrm{~nm}$ and $\mathrm{Ti}=20 \mathrm{~nm}$ ) were prepared using photolithographic and sputtering technique, which serves as a source and drain electrode. The back side of the Si wafer was removed and the layer of Ga-In eutectic was applied in order to form the Ohmic contact and used as a gate terminal. The bottom gate bottom contact field effect transistors in Fig. 1(b) were fabricated having length $\mathrm{L}=20 \mu \mathrm{m}$ and channel width $\mathrm{W}=2 \mathrm{~mm}$. A DekTak profilometer was employed to measure the thickness, $t=70 \mathrm{~nm}$ of the 6CuTBTAP film. Details of the experimental protocols are available from one of our earlier publications. ${ }^{19}$ The characterisations of 6CuTBTAP OFETs were performed at room temperature in air under ambient conditions using a Keithley 4200 semiconductor parameter analyzer. The atomic force microscopic images of the films spin coated on the $20 \mathrm{~mm} \times 20 \mathrm{~mm}$ silicon substrate were examined by the Digital Nanoscope III. The crystallographic study of the 6CuTBTAP thin films prepared onto the Si (110) wafer was performed using an X-ray Diffractometer (model Bruker D8 Advance) with monochromatic $\mathrm{Cu}-\mathrm{K} \alpha$ radiation of wavelength $\lambda=0.1541 \mathrm{~nm}$.

\section{RESULTS AND DISCUSSION}

The AFM micrograph in Fig. 2 shows the polycrystalline surface morphology of the as-prepared 6CuTBTAP spin 

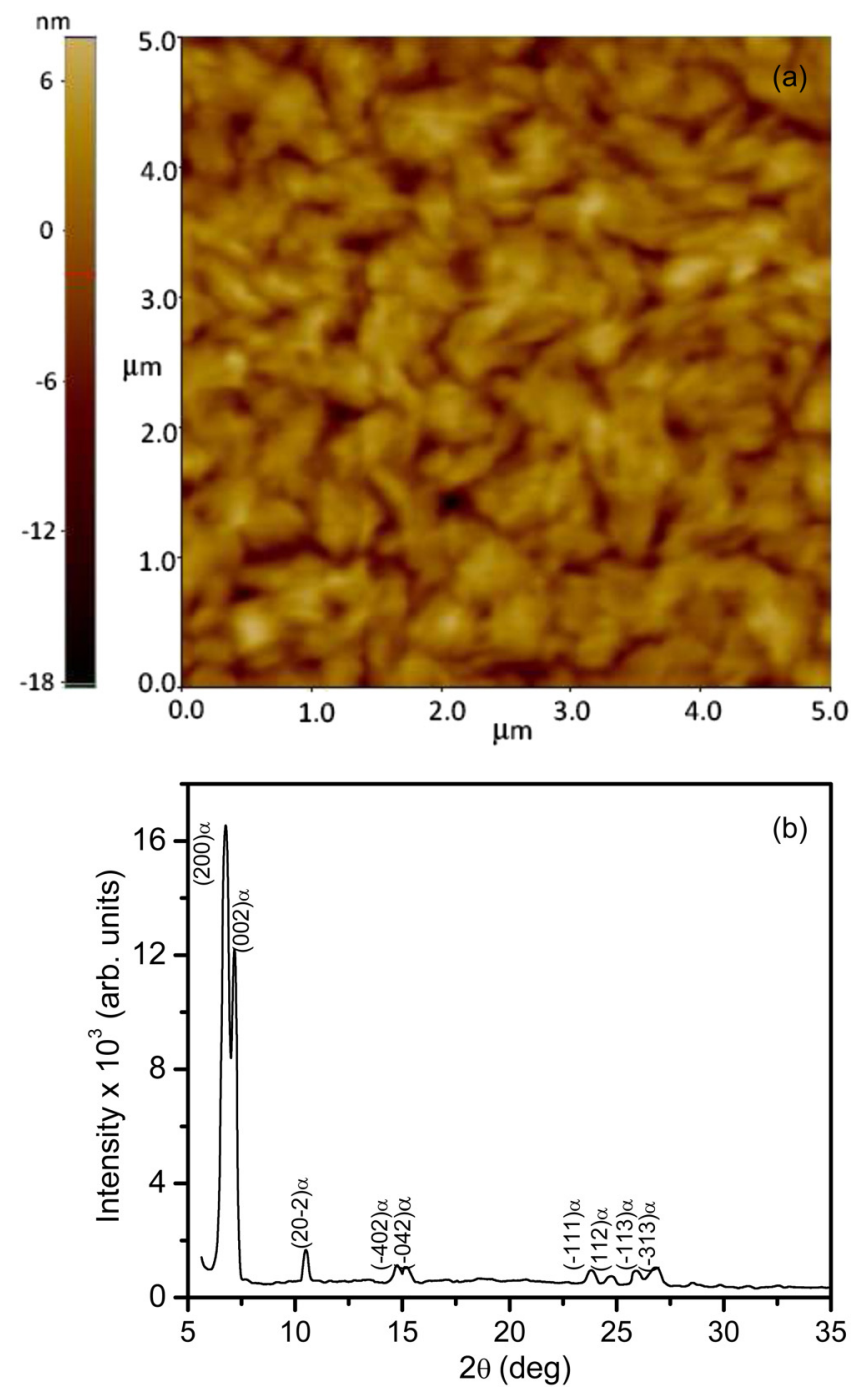

FIG. 2. (a) Two-dimensional AFM micrograph of 6CuTBTAP thin film and (b) X-ray diffraction spectra of spin coated 6CuTBTAP thin film

coated film on the silicon substrate. Non-uniform clusters of size ranging from 1 to $1.5 \mu \mathrm{m}$ can be clearly seen. The size of the cluster is much larger than the 6CuPc layers deposited on the similar substrate under the same type of the preparation conditions. ${ }^{19}$ The large cluster seems to be an agglomeration of small long grain like structures, which are separated by the grain boundaries. These grain boundaries can be further reduced upon the heat treatment procedure at the desired temperature and ambient conditions. The large clusters of 6CuTBTAP formed with long grains could be suitable for fast charge transportation within the active semiconductor, which may further be useful to improve the field effect mobility. The thin layers with small granular morphology have a large number of large grain boundaries where the charge carriers may be trapped. ${ }^{19}$ The X-ray diffraction (XRD) pattern of the spin coated 6CuTBTAP prepared onto the Si substrate is depicted in Fig. 2(b). The multiple diffraction peaks demonstrate the growth of the polycrystalline structure of the layer. All the peaks observed in the XRD spectra are well matched with the $\alpha-\mathrm{CuPc}$ of the monoclinic crystal structure with four molecules per unit cell in Fig. 1(a). It is important to note that the 6CuTBTAP thin film showed a single $\alpha$-phase, whereas the $6 \mathrm{CuPc}$ exhibited mixed $\alpha$ and $\beta$-phases. The average grain size of $\sim 55 \mathrm{~nm}$ was calculated by using the Debye-Scherrer equation. ${ }^{20}$

\section{A. OFET linear analysis}

Figure 3 shows a set of reproducible, hysteresis-free output characteristics of the 6CuTBTAP organic thin film field-effect transistors (OTFTs) in terms of drain-source current $\left(\mathrm{I}_{\mathrm{D}}\right)$ as a function of drain-source voltage $\left(\mathrm{V}_{\mathrm{D}}:-50\right.$ $\mathrm{V} \leq \mathrm{V}_{\mathrm{D}} \geq 0 \mathrm{~V}$ ) as the gate voltage $\mathrm{V}_{\mathrm{G}}$ is varied within the range of $50 \mathrm{~V} \leq \mathrm{V}_{\mathrm{G}} \geq 0 \mathrm{~V}$. The increase of drain-source conductivity with $\mathrm{V}_{\mathrm{G}}$ indicates clean field-effect operation in a p-type accumulation mode. ${ }^{21}$ That the increase of $I_{D}$ with $V_{D}$ for $-10 \mathrm{~V} \leq V_{D} \geq 0 \mathrm{~V}$ is significantly smaller than $V_{D} \geq$ $10 \mathrm{~V}$ is believed to be typical of semiconducting behavior of the 6CuTBTAP active layer. This type of behavior has also been reported for the pentacene-based OTFT with conducting gold electrodes. ${ }^{22}$ Initial estimates have been made for linear field-effect mobility $\mu_{\text {lin }}=0.11 \mathrm{~cm}^{2} / \mathrm{Vs}$ and threshold voltage $\mathrm{V}_{\mathrm{T}}=6 \mathrm{~V}$ from the slope and intercept on the abscissa of the plot of Eq. (1) on linear scales ${ }^{23}$

$$
I_{D}^{l i n}=-\mu_{\text {lin }} \frac{W}{L} \mathrm{C}_{i}\left(V_{G}-V_{T}\right) \mathrm{V}_{D},
$$

for the linear region of $\left|V_{D}\right|<\left|V_{G}-V_{T}\right|$

The transfer characteristic in Fig. 4 of $I_{D}$ versus $V_{G}$ for $V_{D}=-40 \mathrm{~V}$ exhibits an on/off current ratio of $10^{6}$. The positive charges in the 6CuTBTAP device become completely depleted over the entire thickness of the active layers at the gate voltage of $\mathrm{V}_{\mathrm{G}}=5 \mathrm{~V}$. This depletion is caused by the band bending of the active Pc layers in the opposite direction at the gate.

Values of saturated field-effect mobility $\mu_{\text {sat }}$ and threshold voltage $\mathrm{V}_{\mathrm{T}}$ are estimated to be $0.15 \mathrm{~cm}^{2} \mathrm{~V}^{-1} \mathrm{~s}^{-1}$ and $6 \mathrm{~V}$, respectively, from the slope and the intercept of the best linear fits in Fig. 4 to the square-root dependence

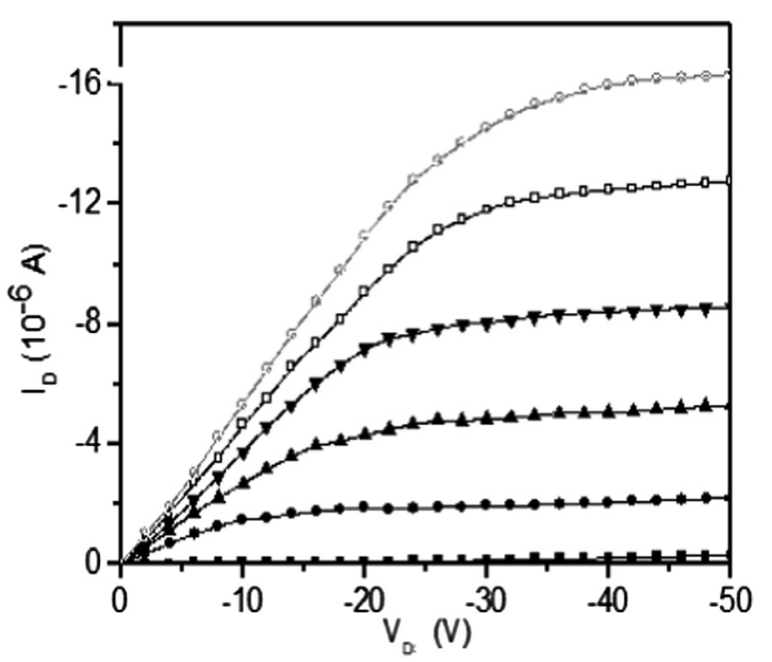

FIG. 3. Output characteristics: drain-to-source current $\left(\mathrm{I}_{\mathrm{D}}\right)$ as a function of the drain-to-source voltage $\left(\mathrm{V}_{\mathrm{D}}\right)$ between $-50 \mathrm{~V} \leq \mathrm{V}_{\mathrm{D}} \geq 0 \mathrm{~V}$ for gate voltage $\mathrm{V}_{\mathrm{G}}: \mathrm{V}_{\mathrm{G}}=0 \mathrm{~V}(\boldsymbol{\square}), \mathrm{V}_{\mathrm{G}}=-10 \mathrm{~V}(\boldsymbol{\bullet}), \mathrm{V}_{\mathrm{G}}=-20 \mathrm{~V}(\boldsymbol{\Delta}), \mathrm{V}_{\mathrm{G}}=-30 \mathrm{~V}(\boldsymbol{\nabla}), \mathrm{V}_{\mathrm{G}}=$ $-40 \mathrm{~V}(\square)$, and $\mathrm{V}_{\mathrm{G}}=-50 \mathrm{~V}(\mathrm{O})$. 


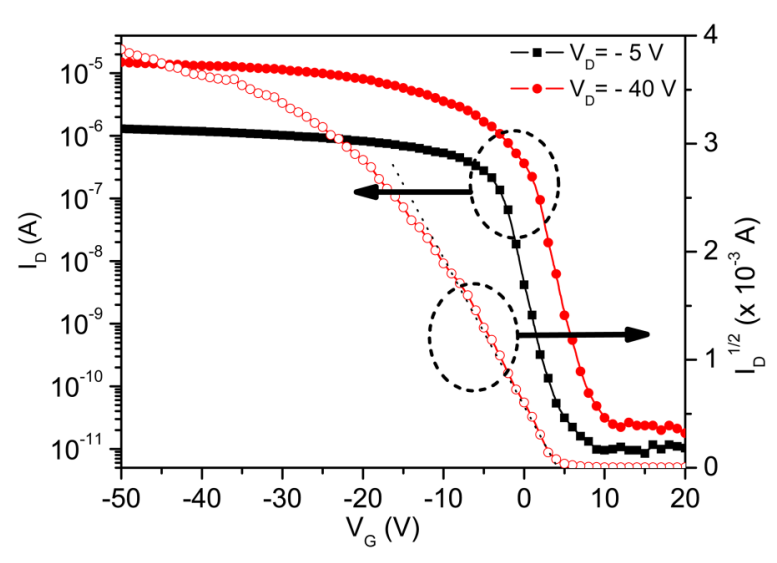

FIG. 4. Transfer characteristics $\mathrm{V}_{\mathrm{D}}=-5 \mathrm{~V}$ and $\mathrm{V}_{\mathrm{D}}=-40 \mathrm{~V}$ plots of square root of $\mathrm{I}_{\mathrm{D}}$ vs $\mathrm{V}_{\mathrm{G}}$ for OTFTs with a 6CuTBTAP active layer.

of $I_{D}$ on $V_{G}$ in the form ${ }^{23}$

$$
I_{D}=\mu_{\text {sat }} \frac{W}{2 L} \mathrm{C}_{i}\left(V_{G}-V_{T}\right)^{2},
$$

for a saturation region of $V_{D}>V_{G}$.

Investigations have been made in recent years on similarly configured OTFTs using $70 \mathrm{~nm}$ thick spin-coated active layers of octakis(hexyl) copper phthalocyanine $(6 \mathrm{CuPc})$ analog compounds. ${ }^{24}$ Room temperature transistor characteristics have been reported for OTFTs employing $100 \mathrm{~nm}$ thick spin-cast polycrystalline active layers of thermally converted copper tetrabenzoporphyrin (CuTBP) compounds at $165^{\circ} \mathrm{C}$ in vacuum from amorphous, insulating thin-films of copper tetrabicycloporphyrin. ${ }^{25}$ The device parameters of these transistors have been evaluated from Eqs. (1) and (2), and the results are summarised in Table I. Active layers of various metal tetrabenzoporphyrins were produced for the OFETs by annealing the metal-tetrabicycloporphyrin film spin coated from precursor solution in chloroform, For example, the values of $\mu_{\text {sat }}$ and on-off ratio were measured to be $0.017 \mathrm{~cm}^{2} \mathrm{~V}^{-1} \mathrm{~s}^{-1}$ and $10^{5}$ for thin films of metal-free 1,4:8,11:15,18:22,25Tetraethano-29H,31H-tetrabenzoporphine having the optimal thickness lying between $10 \mathrm{~nm}$ and $100 \mathrm{~nm}$ annealed at $210^{\circ} \mathrm{C}$ for $5 \mathrm{~min}^{26}$ The values of $\mu_{\text {sat }}$ and the on-off ratio of OFETs based on $100 \mathrm{~nm}$ thick ZnTBP films as active layers were estimated to be $10^{-2} \mathrm{~cm}^{2} \mathrm{~V}^{-1} \mathrm{~s}^{-1}$ and $10^{2}$, respectively. ${ }^{27}$ The highest value of $\mu_{\text {sat }}$ is found to be $0.22 \mathrm{~cm}^{2} \mathrm{~V}^{-1} \mathrm{~s}^{-1}$ for NiTBPOFET. ${ }^{28}$ 6CuTBTAP molecules are, therefore, found to provide better room temperature field effect performance in terms of higher mobility, two orders of magnitude increase in on/off ratio, and smaller sub-threshold swing than both devices based on its TBP compounds.

\section{B. Analysis of OFET with polycrystalline active layers}

However, Eqs. (1) and (2), commonly used for the transistors with a single crystalline active layer, are based on gradual channel approximations for the drain current relation in which a linear potential profile across the channel between the gate and the source is assumed to exist. ${ }^{29}$ The charge carriers induced by the gate voltage in the channel become trapped in the polycrystalline film as observed in the AFM pictures for the present $6 \mathrm{CuTBTAP}$ film. The ratio of free carriers to trapped carriers increases with the increasing gate voltage, leading to a power law dependence of the carrier mobility upon the gate voltage $\mathrm{V}_{\mathrm{G}}$ in the form of $\mu=\mu_{0}\left[V_{G}-\left(R_{S}+R_{D}\right) I_{D}\right]^{\gamma}$ according to the transit time between the source and drain electrodes, where $\mu_{0}$ is a fitting parameter. ${ }^{30}$ Secondly, acceptor states are found from the $a b$ initio study on band structure to be induced by interactions between the $3 d$ states of $\mathrm{Cu}$ and $\pi$ states of the TBTAP molecule near the bandgap. The active 6CuTBTAP layer, therefore, is likely to form Schottky type contacts with both source and drain gold $(\mathrm{Au})$ electrodes. ${ }^{31}$ As shown in Fig. 1(b), the contact resistances $R_{S}$ and $\mathrm{R}_{\mathrm{D}}$ at the source and the drain contacts also govern the current $\mathrm{I}_{\mathrm{D}}$. The voltage between the gate and the source can now be written in the modified form of $V_{G}-R_{S} I_{D}$ while that between the source and the drain is $V_{D}-\left(R_{S}+R_{D}\right) I_{D}$. These two voltages control the drain current $I_{D}$.

The drain current $I_{D(l i n)}$ is, therefore, written in terms of the field independent mobility $\mu_{0}$ and the threshold voltage $\mathrm{V}_{\mathrm{T}}$ in the form ${ }^{32}$

$$
I_{D(\text { lin })}=\left(\frac{\mu_{0} C_{i} W}{L}\right)\left(\frac{V_{D}\left(V_{G}-V_{T}\right)^{(\gamma+1)}}{1+\left(R_{S}+R_{D}\right)\left(V_{G}-V_{T}\right)^{(\gamma+1)}}\right)
$$

for the linear region.

The voltage drop across $R_{D}$ in the saturation regime is not large enough for significant control of the drain-source current and the saturation current $\mathrm{I}_{\mathrm{D}(\mathrm{Sat})}$ can therefore be written in the form

$$
\mathrm{I}_{\mathrm{D}(\mathrm{sat})}=\left(\frac{\mu_{0} \mathrm{C}_{\mathrm{i}} \mathrm{W}}{(\gamma+2) \mathrm{L}}\right)\left(\mathrm{V}_{\mathrm{G}}-\mathrm{R}_{\mathrm{S}} \mathrm{I}_{\mathrm{D}}-\mathrm{V}_{\mathrm{T}}\right)^{(\gamma+2)}
$$

for the saturation region.

The exponent $\gamma=2\left(\frac{T_{C}}{T}-1\right)$ is associated with the characteristic temperature $T_{C}$ for the width of the Gaussian or slope of the exponential distribution of traps and $\mathrm{T}$ is room temperature. For $\mathrm{T}_{\mathrm{C}}=\mathrm{T}$, the transistor is expected to behave more like the one predicted by Eqs. (1) and (2).

Using MATLAB's curve fitting routine "Isqcurvefit,"

\begin{tabular}{|c|c|c|c|c|c|c|}
\hline \multirow[b]{2}{*}{ Compound } & \multicolumn{2}{|c|}{ Mobility $\left(\mathrm{cm}^{2} / \mathrm{Vs}\right)$} & \multirow{2}{*}{$\begin{array}{c}\text { On/off } \\
\text { current ratio }\end{array}$} & \multirow{2}{*}{$\begin{array}{l}\text { Threshold voltage } \\
\qquad\left(\mathrm{V}_{\mathrm{T}}\right) \mathrm{V}\end{array}$} & \multirow{2}{*}{$\begin{array}{l}\text { Sub-threshold } \\
\mathrm{S} \text { (V/decade) }\end{array}$} & \multirow{2}{*}{$\begin{array}{l}\text { Interface trap density } \\
\mathrm{N}_{\mathrm{SS}}\left(\times 10^{12} \mathrm{~cm}^{-2}\right)\end{array}$} \\
\hline & $\mu_{\operatorname{lin}}$ & $\mu_{\text {sat }}$ & & & & \\
\hline 6CuTBTAP & 0.11 & 0.15 & $\sim 10^{6}$ & 6 & 1.49 & 1.32 \\
\hline 6CuPc (Ref. 21) & $4 \times 10^{-6}$ & 0.04 & $\sim 10^{7}$ & 9 & 1.88 & 1.72 \\
\hline CuTBP (Ref. 22) & 0.1 & 0.13 & $\sim 10^{4}$ & 5 & 4.2 & $\ldots$ \\
\hline
\end{tabular}
values of $4.9 \times 10^{-6} \mathrm{~cm}^{2} \mathrm{~V}^{-1} \mathrm{~s}^{-1}, 0.117$, and $3.9 \mathrm{~V}$ have been

TABLE 1. OFET parameters estimated from Eqs. (1) to (4) using 6CuTBTAP, 6CuPc, and CuTBP films as active layers. 
estimated for parameters $\mu_{0}, \gamma$, and $V_{T}$ in Eqs. (3) and (4), respectively. The least square method has been used to find these three parameters subject to the minimisation of the sum of square fitting errors. Values of $\mathrm{T}_{\mathrm{C}}$ and the corresponding Meyer-Neldel energy $\mathrm{E}_{\mathrm{MN}}\left(=\mathrm{kT}_{\mathrm{C}}\right)$ are estimated to be 317.6 $\mathrm{K}$ and $27.37 \mathrm{meV}$, respectively. The ratio of $\frac{\mathrm{E}_{\mathrm{MN}}}{\mathrm{kT}} \neq 1$ suggests that trapped charges do not contribute to the drain to source current and therefore the mobility becomes largely dependent upon the ratio of trapped-to-free carriers controlled by $\mathrm{V}_{\mathrm{G}} \cdot{ }^{33}$ The value of $\mathrm{V}_{\mathrm{T}}=3.9 \mathrm{~V}$ is smaller than the one previously determined (2), and this may be attributed to the bulk trap limited charge transport in the polycrystalline 6CuTBTAP layer and the value of the trap density $\mathrm{N}_{\mathrm{B}}$ is found to be $5.6 \times 10^{17} \mathrm{~cm}^{-3}$ in the form ${ }^{34}$

$$
N_{B}=\frac{V_{T}^{2} C_{i}^{2}}{2 \varepsilon_{\mathrm{TBTAP}} \varepsilon_{0} \mathrm{kT}} .
$$

The free space permittivity $\varepsilon_{0}=8.85 \times 10^{-12} \mathrm{Fm}^{-1}$ and the dielectric constant of 6 CuTBTAP film $\varepsilon_{\mathrm{TBTAP}} \approx 3.0$ were used for the calculations.

The value of sub-threshold swing $S$ defined in Eq. (6) as the gate voltage $V_{G}$ required to increase $I_{D}$ by a factor of ten is found to be $1.49 \mathrm{~V}$ decade $^{-1}$ from the transfer characteristics using the relation

$$
S=\frac{d V_{G}}{d\left(\log _{10} I_{D}\right)} .
$$

The value of $1.32 \times 10^{12} \mathrm{~cm}^{2}$ is estimated for the density $\mathrm{N}_{\mathrm{ss}}$ of traps at the interface between the organic layer and the gate $\mathrm{SiO}_{2}$ dielectrics from knowledge of the sub-threshold voltage swing $\mathrm{S}$ in the form ${ }^{35}$

$$
\mathrm{N}_{\mathrm{ss}}=\left[\frac{\mathrm{S} \log (\mathrm{e})}{\mathrm{kT}}-1\right] \frac{\mathrm{C}_{\mathrm{i}}}{q},
$$

where $\mathrm{q}=1.6 \times 10^{-19} \mathrm{C}$ is the elementary electronic charge, $\mathrm{k}=8.62 \times 10^{-19} \mathrm{eVK}^{-1}$, and the temperature $\mathrm{T}$ is taken to be $300 \mathrm{~K}$. Apart from structural imperfections due to molecular misalignment at the interface, non-stoichiometric depositions,

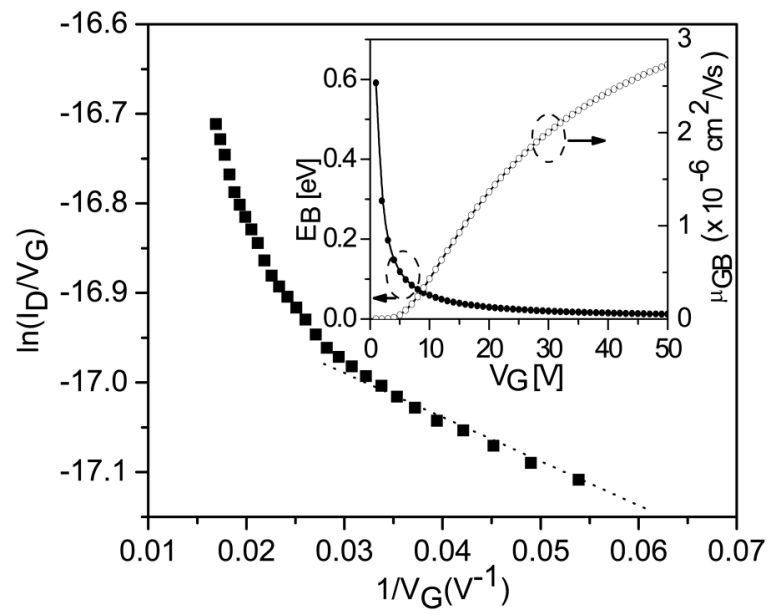

FIG. 5. Levinson plot for $\mathrm{V}_{\mathrm{D}}=-5 \mathrm{~V}$ 6CuTBTAP films and the inset showing the dependence of interfacial barrier (solid circles) and the grain boundary mobility (open circles). and surface roughness of the 6CuTBTAP film are believed to have contributed to the value of $\mathrm{N}_{\mathrm{ss}} .{ }^{36}$

The value of $1.46 \times 10^{12} \mathrm{~cm}^{-2}$ for the density $\mathrm{N}_{\mathrm{g}}$ of traps at the grain boundaries per unit area in the active layers has been estimated from the slope of the best linear fit to the Levinson plot in Fig. 5 of $\ln \left(\frac{\mathrm{I}_{\mathrm{D}}}{V_{G}}\right)$ as a function of $\frac{1}{\mathrm{~V}_{\mathrm{G}}}$ for $\mathrm{V}_{\mathrm{D}}=-5 \mathrm{~V}$ in the form

$$
I_{D}=\mu_{\mathrm{GB} 0} V_{D} \frac{W}{L} C_{i} V_{G} \exp \left(-\frac{q^{3} N_{g}^{2} t}{8 \varepsilon_{0} \varepsilon_{\mathrm{TBTA}} \mathrm{kTC}_{i} V_{G}}\right),
$$

where $\mu_{\mathrm{GBO}}$ is the trap free mobility which usually depends on the grain size and the carrier concentration, but only slightly on measurement temperature. ${ }^{37} \mu_{\mathrm{GBO}}$ is found to be $0.82 \times 10^{-2} \mathrm{~cm}^{-2} / \mathrm{Vs}$ from the intercept of the plot. It is also to be noted that the Levinson plot in the present case is not a strictly straight line. This may indicate that the grain boundaries may act as traps rather than barriers. ${ }^{38}$ The inset of Fig. 5 shows that the grain boundary barrier $\left(E_{B}=\frac{q^{3} N_{g}^{2} t}{8 \varepsilon_{0} \varepsilon_{\mathrm{TBTA}} \mathrm{C}_{i} V_{G}}\right)$ decreases while the grain boundary mobility $\mu_{\mathrm{GB}}$ increases with $V_{G} . E_{B}$ is found to undergo sharp decreases at low voltage $V_{G} \leq V_{T}$, and then the reduction tends to be steady. Similar calculations have been reported for the top $\mathrm{Au}$ contact pentacene OFETs. The density $\mathrm{N}_{\mathrm{g}}$ is believed to contribute to the parasitic resistance of the device. ${ }^{39}$

As shown in Fig. 6, the mobilities in both linear and saturation regions corresponding to $\mathrm{V}_{\mathrm{D}}=-5 \mathrm{~V}$ and $\mathrm{V}_{\mathrm{D}}=-45 \mathrm{~V}$ were determined from Eqs. (3) and (4), respectively, as a function of gate voltage $\mathrm{V}_{\mathrm{G}}$. These values of the mobilities are at least one order of magnitude smaller than those obtained earlier using Eqs. (1) and (2). A sharp increase in $\mu_{\text {sat }}$ is observed from $3.0 \times 10^{-2} \mathrm{~cm}^{2} \mathrm{~V}^{-1} \mathrm{~s}^{-1}$ to $4.8 \times 10^{-2}$ $\mathrm{cm}^{2} \mathrm{~V}^{-1} \mathrm{~s}^{-1}$ as $\mathrm{V}_{\mathrm{G}}$ is increased from $\mathrm{V}_{\mathrm{G}}=0 \mathrm{~V}$ to $\mathrm{V}_{\mathrm{G}} \approx \mathrm{V}_{\mathrm{T}}$ and $\mu_{\text {sat }}$ then tends to reach the saturation value of $6.9 \times 10^{-2}$ $\mathrm{cm}^{2} \mathrm{~V}^{-1} \mathrm{~s}^{-1}$ slowly at $\mathrm{V}_{\mathrm{G}}=50 \mathrm{~V}$. This dependence can be expressed as $\mu_{\text {sat }} \propto \exp \sqrt{B V}$ as shown in the inset of Fig. 6 . This type of behavior may be identified with the Poole Frankel charge transport mechanism and the value of $\beta$ is

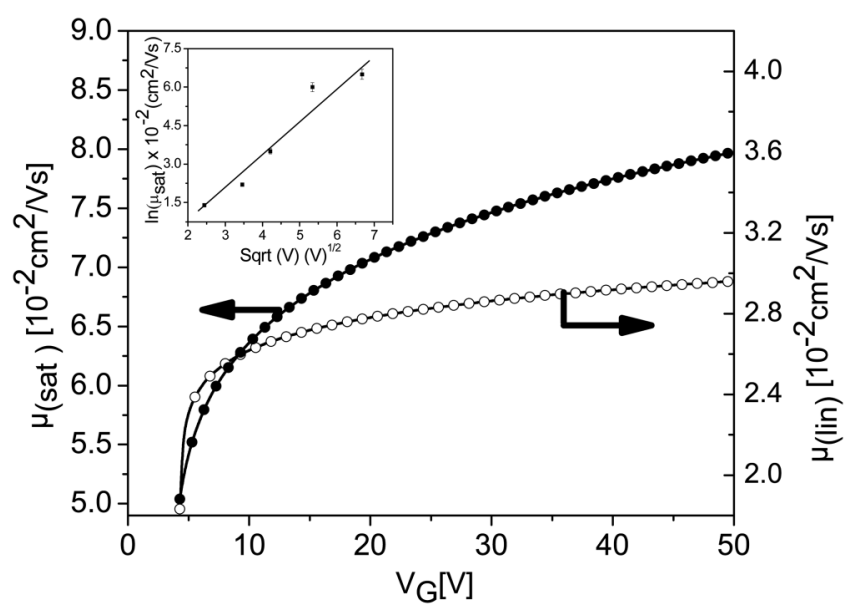

FIG. 6. Dependences on the gate voltage $V_{G}$ of $\mu_{\text {sat }}$ for $V_{D}=-45 V$ (solid circles) and $\mu_{\text {lin }}$ for $V_{D}=-5 \mathrm{~V}$ (solid circles) for $\mathrm{V}_{\mathrm{D}}=-5 \mathrm{~V}$ (open circles) and log-linear Poole-Frankel plot of $\mu_{\text {sat }}$ and $\sqrt{ } \mathrm{V}$ (inset). 
estimated to be $\sim 1.33 \times 10^{-2} \mathrm{~cm}^{2} / \mathrm{V}^{3 / 2} \mathrm{~s}$ from the slope of the linear fit to the plot of $\ln \mu_{\text {sat }}$ vs $\sqrt{ } \mathrm{V}$ on a log-linear scale and this positive value of $\beta$ implies that the positional order is small in comparison with the width of the Gaussian density of energy states. ${ }^{40}$ Similarly configured OFETs using the seven monolayer thick Langmuir-Blodgett film of liquid crystalline 2,3,9,10,16,17,23,24-octakis((2cinnamyl) ethoxy) phthalocyaninato copper molecules exhibit a similar field dependence of the saturated mobility $\mu_{\text {sat }}$ with the highest value of $1.8 \times 10^{-2} \mathrm{~cm}^{2} \mathrm{~V}^{-1} \mathrm{~s}^{-1}$ at $V_{G}=40 \mathrm{~V},{ }^{41}$ which is found to be smaller than the corresponding value of the 6CuTBTAP molecule by a factor of more than three. The release of these charge carriers at high gate voltages results in a large increase in the drain current of the device due to the field enhanced thermal excitation. ${ }^{42}$ The variation of $\mu_{\text {lin }}$ with $V_{G}$ follows a similar pattern, $\mu_{\text {lin }}$ varying between $1.8 \times 10^{-2} \mathrm{~cm}^{2} \mathrm{~V}^{-1} \mathrm{~s}^{-1}$ and $6.7 \times 10^{-2} \mathrm{~cm}^{2} \mathrm{~V}^{-1} \mathrm{~s}^{-1}$ and $V_{G}$ between $0 \mathrm{~V}$ and $\mathrm{V} 50 \mathrm{~V}$.

The contact resistance $R_{S D}=\left(R_{S}+R_{D}\right)$ is determined numerically from Eq. (3) as a function of $V_{G}$ for constant $V_{D}=-5 \mathrm{~V}$. Figure 7 shows the decrease of $\mathrm{R}_{\mathrm{SD}}$ from $75 \mathrm{M} \Omega$ to $5 \mathrm{M} \Omega$ in an exponential form of $\mathrm{R}_{\mathrm{SD}} \propto \exp \left(-\gamma \mathrm{V}_{\mathrm{G}}\right)$. However, the decrease is sharper for the range $\mathrm{V}_{\mathrm{G}} \leq 10 \mathrm{~V}$ than that of $\mathrm{V}_{\mathrm{G}}>10 \mathrm{~V}$ with the corresponding values of $16.1 \times 10^{-3} \mathrm{~V}^{-1}$ and $5.6 \times 10^{-3} \mathrm{~V}^{-1}$ for the exponent $\gamma$. The contact effects in pentacene based OFETs have been investigated by using different metal electrodes and the values of the contact resistance which are extracted by introducing $\mathrm{R}_{\mathrm{SD}}$ into Eq. (1) are greater than those reported in the present investigation by nearly one order of magnitude. ${ }^{42,43}$ The contact resistance at the Au electrode and the 6CuTBTAP spun active layers arises from the potential difference between the HOMO of an organic semiconductor and work function of the metal drain electrode. Undoped 6CuTBTAP molecules are regarded being p-type intrinsic semiconductors having a very low charge concentration at thermal equilibrium due to their wide bandgap of $1.77 \mathrm{eV}$ as reported earlier. This leads to the existence of the thick depletion layer at the Au/6CuTBTAP interface prohibiting the carrier injection by tunneling. ${ }^{44}$ It is to be noted here that the increase of $\mu_{\text {sat }}$ with $V_{G}$ is associated with the decrease in $\mathrm{R}_{\mathrm{SD}}$. This behavior may be attributed to the current crowding as a greater charge density is induced in the accumulation channel by increasing $\mathrm{V}_{\mathrm{G}} \cdot{ }^{45}$

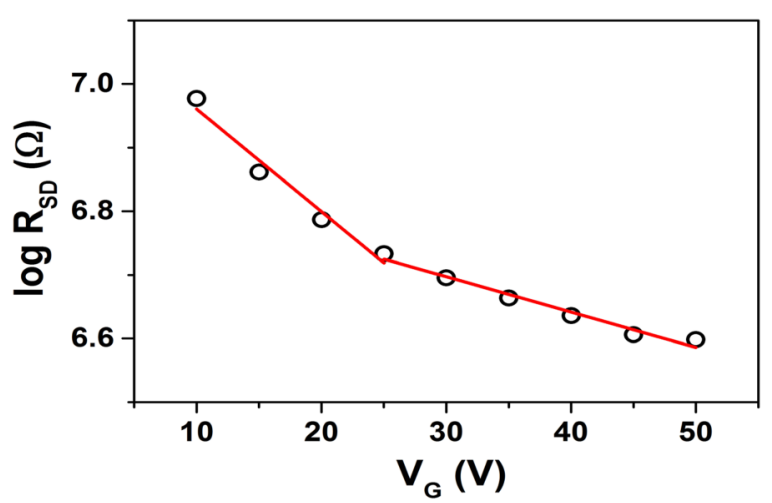

FIG. 7. Dependence of the contact resistance $R_{S D}$ on the gate voltage $V_{G}$ for $\mathrm{V}_{\mathrm{D}}=-5 \mathrm{~V}$ 6CuTBTAP films on linear-linear and log-linear scales.

\section{CONCLUDING REMARKS}

Newly synthesised non-peripherally octahexyl-substituted copper tetrabenzotriazaporphyrin (6CuTBTAP) compounds have been successfully solution-processed at room temperature on an active semiconducting layer for fabrication of organic field effect transistors on a highly n-doped $\mathrm{Si}$ wafer (110) gate substrate. The technique may easily be adopted for the deposition over a large area for flexible electronics. The molecules are rare examples of unsymmetrical Pc-like structures. Values of saturation mobility $\left(\mu_{\text {sat }}=0.15 \mathrm{~cm}^{2} / \mathrm{Vs}\right)$, sub-threshold voltage swing $(S=1.49 \mathrm{~V} /$ decade $)$, threshold voltage $\left(\mathrm{V}_{\mathrm{T}}=6 \mathrm{~V}\right)$, and on-off ratio $\left(10^{6}\right)$ are very promising when compared to parameters for transistors based on other small molecules within other tetrabenzotriazaporphyrin and tetrabenzoporphyrin analogs. Values of the mobility and threshold voltage estimated from the linear potential profile across the channel between the gate and the source are larger than those extracted from power law dependence of the carrier mobility upon the gate voltage appropriate to the polycrystalline morphology of the active layer and incorporating the contact effects. This demonstrates the importance of the dispersive nature of charge transport. The size of the cluster may be further improved upon annealing the layers at an elevated temperature and the larger particle size is expected to increase the carrier mobility.

\section{ACKNOWLEDGMENTS}

Experimental work was carried out at Queen Mary University of London under financial support from the UK Technology Strategy Board (Project No. TP/6/EPH/6/S/ K2536J). The pre-patterned transistor substrates were prepared by QUDOS Technology, Rutherford Appleton Laboratory, Didcot, UK. The authors are grateful to Dr. Craig E. Murphy and Dr. Markys G. Cain of the National Physical Laboratory, Hampton Road, Teddington, Middlesex, UK, for fruitful discussions.

\footnotetext{
${ }^{1}$ V. V. Kalashnikov, V. E. Pushkarev, and L. G. Tomilova, "Tetrabenzotriazaporphyrins synthesis, properties and application," Russ. Chem. Rev. 83(7), 657-675 (2014).

${ }^{2}$ C. M. B. Carvalho, T. J. Brocksom, and K. T. de Oliveira, "Tetrabenzoporphyrins synthetic developments and applications," Chem. Soc. Rev. 42(8), 3302-3317 (2013).

${ }^{3}$ A. N. Cammidge, I. Chambrier, M. J. Cook, and L. Sosa-Vargas, "Synthesis and properties of the hybrid phthalocyanine-tetrabenzoporphyrin macrocycles," in Handbook of Porphyrin Science, edited by K. M. Kadish, K. M. Smith, and R. Guilard (World Scientific Publishing, Singapore, 2012), Vol. 16, pp. 331-404.

${ }^{4}$ A. Diaz-Moscoso, G. J. Tizzard, S. J. Coles, and A. N. Cammidge, "Synthesis of meso-substituted tetrabenzotriazaporphyrins: Easy access to hybrid macrocycles," Angew. Chem. Int. Ed. 52(41), 10784-10787 (2013).

${ }^{5}$ K. Liou, M. Y. Ogawa, T. P. Newcomb, G. Quirion, M. Lee, M. Poirier, W. P. Halperin, B. M. Hoffman, and J. A. Ibers, "Preparation, characterization, and low temperature transition of $\mathrm{Cu}($ tatbp)I, a new porphyrinic conductor with local moments coupled to itinerant charge carriers," Inorg. Chem. 28, 3889-3896 (1989).

${ }^{6}$ G. Quirion, M. Poirier, M. Y. Ogawa, and B. M. Hoffman, "Microwave dielectric properties of $\mathrm{Cu}($ tatbp)I," Solid-State Commun. 64(4), 613-616 (1987).

${ }^{7}$ G. Quirion, M. Poirier, M. Y. Ogawa, and B. M. Hoffman, "Magnetic local-moment effects in the quasi-one-dimensional conductor Cu(triazatetrabenzporphyrinato)I," Phys. Rev. B Rapid Commun. 37, 4274-4275 (1988).
} 
${ }^{8}$ W. B. Euler, J. Martinsen, L. J. Pace, B. M. Hoffman, and J. A. Ibers, "Carrier properties of porphyrinic molecular metals," Mol. Cryst. Liq. Cryst. 81, 231-242 (1982).

${ }^{9}$ B. M. Hoffman and J. A. Ibers, "Porphyrinic molecular metals," Acc. Chem. Res. 16, 15-21 (1983).

${ }^{10}$ M. R. Godfrey, T. P. Newcomb, B. M. Hoffman, and J. A. Ibers, "Spin pairing and magnetic coupling in quasi one-dimensional semiconductors with a trimeric stacking structure. Structural, charge-transport, and magnetic studies of $[\mathrm{Ni} \text { (tatbp) }]_{3}\left[\mathrm{ReO}_{4}\right]_{2} \cdot \mathrm{C}_{10} \mathrm{H}_{7} \mathrm{Cl}$ and $\left[\mathrm{Cu}(\text { tatbp) }]_{3}\left[\mathrm{ReO}_{4}\right]_{2} \cdot \mathrm{C}_{10} \mathrm{H}_{7} \mathrm{Cl}\right.$," J. Am. Chem. 112, 7260-7269 (1990).

${ }^{11}$ A. N. Cammidge, I. Chambrier, M. J. Cook, E. H. G. Langner, M. Rahman, and J. C. Swarts, "Characterization, liquid crystallinity and spin-coated films of some metalated1,4,8,11,15,18,22,25-octaalkyl tetrabenzo[b,g,1,q][5,10,15]triazaporphyrin derivatives," J. Porphyr. Phthalocyanines 15, 890-897 (2011).

${ }^{12}$ Z. R. Chen and W. H. Yu, "Theoretical study of the optical and charge transport properties in non-peripherally octasubstituted phthalocyaninetetrabenzoporphyrin hybrids," Mol. Phys. 115(4), 424-431 (2017).

${ }^{13}$ M. Nishi, M. Matsuda, N. Hoshino, and T. Akutagawa, "Comparison of structural and electrical characteristics between tetrabenzoporphyrin- and phthalocyanine-based charge-transfer complexes," Chem. Lett. 44(3), 390-392 (2015).

${ }^{14}$ K. Takahashi, B. W. Shan, X. M. Xu, S. J. Yang, T. Koganezawa, D. Kuzuhara, N. Aratani, M. Suzuki, Q. Miao, and H. Yamada, "Engineering thin films of a tetrabenzoporphyrin toward efficient chargecarrier transport: Selective formation of a brickwork motif," ACS Appl. Mater. Interfaces 9(9), 8211-8218 (2017).

${ }^{15}$ N. B. Chaure, A. N. Cammidge, I. Chambrier, M. J. Cook, and A. K. Ray, "A tetrabenzotriazaporphyrin based organic thin film transistor: Comparison with a device of the phthalocyanine analogue," ECS J. Solid State Sci. Technol. 4(4), P3086-P3090 (2015).

${ }^{16}$ J. A. J. Jimenez Tejada, P. L. Lopez Varo, A. N. Cammidge, I. Chambrier, M. J. Cook, N. B. Chaure, and A. K. Ray, "Compact modeling of organic thin-film transistors with solution processed octadecyl substituted tetrabenzotriazaporphyrin as an active layer," IEEE Trans. Electron Devices 64(6), 2629-2634 (2017).

${ }^{17}$ A. N. Cammidge, I. Chambrier, M. J. Cook, D. L. Hughes, M. Rahman, and L. Sosa-Vargas, "Phthalocyanine analogues: Unexpectedly facile access to non-peripherally substituted octaalkyl tetrabenzotriazaporphyrins, tetrabenzodiazaporphyrins, tetrabenzomonoazaporphyrins and tetrabenzoporphyrins," Chem. Eur. J. 17(11), 3136-3146 (2011).

${ }^{18}$ J. Mack, L. Sosa-Vargas, S. J. Coles, G. J. Tizzard, I. Chambrier, A. N. Cammidge, M. J. Cook, and N. Kobayashi, "Synthesis, characterization, MCD spectroscopy, and TD-DFT calculations of copper-metalated nonperipherally substituted octaoctyl derivatives of tetrabenzotriazaporphyrin, cis- and trans-tetrabenzodiazaporphyrin, tetrabenzomonoazaporphyrin, and tetrabenzoporphyrin," Inorg. Chem. 51, 12820-12833 (2012).

${ }^{19}$ N. B. Chaure, C. Pal, S. Barard, T. Kreouzis, A. K. Ray, A. N. Cammidge, I. Chambrier, M. J. Cook, C. E. Murphy, and M. G. Cain, "A liquid crystalline copper phthalocyanine derivative for high performance organic thin film transistors," J. Mater. Chem. 22, 19179-19189 (2012).

${ }^{20}$ B. D. Cullity and S. R. Stock, Elements of X-ray Diffraction, 3rd ed. (Prentice Hall, Upper Saddle River, NJ, 2001), pp. 152-153.

${ }^{21}$ C. Reese, M. Roberts, M. M. Ling, and Z. N. Bao, "Organic thin film transistors," Mater. Today 7(9), 20-27 (2004).

${ }^{22}$ H. S. Kang, J. W. Lee, M. K. Kim, J. Joo, J. M. Ko, and J. Y. Lee, "Electrical characteristics of pentacene-based thin film transistor with conducting poly(3,4-ethylenedioxythiophene) electrodes," J. Appl. Phys. 100(6), 064508 (2006).

${ }^{23}$ S. M. Sze, Physics of Semiconductor Devices (Wiley, New York, 1981).

${ }^{24}$ N. B. Chaure, A. N. Cammidge, I. Chambrier, M. J. Cook, M. G. Cain, C. E. Murphy, C. Pal, and A. K. Ray, "High-mobility solution-processed copper phthalocyanine-based organic field-effect transistors," Sci. Technol. Adv. Mater. 12, 025991 (2011).

${ }^{25}$ P. B. Shea, L. R. Pattison, M. Kawano, C. Chen, J. H. Chen, P. Petroff, D. C. Martin, H. Yamada, N. Ono, and J. Kanicki, "Solution-processed polycrystalline copper tetrabenzoporphyrin thin-film transistors," Synth. Met. 157(I4-5), 190-197 (2012).

${ }^{26}$ S. Aramaki, Y. Sakai, and N. Ono, "Solution-processible organic semiconductor for transistor applications: Tetrabenzoporphyrin," Appl. Phys. Lett. 84(12), 2085-2087 (2004).

${ }^{27}$ P. B. Shea, H. Yamada, N. Ono, and J. Kanicki, "Solution-processed zinc tetrabenzoporphyrin thin-films and transistors," Thin Solid Films 520(11), 4031-4035 (2012).

${ }^{28}$ P. B. Shea, J. Kanicki, L. R. Pattison, P. Petroff, M. Kawano, H. Yamada, and N. Ono, "Solution-processed nickel tetrabenzoporphyrin thin-film transistors," J. Appl. Phys. 100(3), 034502 (2006).

${ }^{29} \mathrm{M}$. Weis, "Gradual channel approximation models for organic field-effect transistors: The space-charge field effect," J. Appl. Phys. 111(5), 054506 (2012).

${ }^{30}$ P. B. Shea, J. Kanicki, and N. Ono, "Field-effect mobility of polycrystalline tetrabenzoporphyrin thin-film transistors," J. Appl. Phys. 98(1), 014503 (2005).

${ }^{31}$ P. B. Shea and J. Kanicki, "Ab initio electronic structure calculations of solid, solution-processed metallotetrabenzoporphyrins," J. Appl. Phys. 111(7), 073709 (2017).

${ }^{32}$ D. Natali, L. Fumagalli, and M. Sampietro, "Modeling of organic thin film transistors: Effect of contact resistances," J. Appl. Phys. 101(1), 014501 (2007).

${ }^{33}$ V. Rani, A. Sharma, and S. Ghosh, "Charge carrier transport in polycrystalline organic thin film based field effect transistors," AIP Conf. Proc. 1731, 120027 (2016).

${ }^{34}$ J. H. Schon and B. Batlogg, "Trapping in organic field-effect transistors," J. Appl. Phys. 89(1), 336-342 (2001).

${ }^{35}$ C. Y. Kagan and P. W. E. Andry, Thin Film Transistors (Dekker, New York, 2003), p. 87.

${ }^{36}$ P. J. Diemer, Z. A. Lamport, Y. C. Mei, J. W. Ward, K. P. Goetz, W. Li, M. M. Payne, M. Guthold, J. E. Anthony, and O. D. Jurchescu, "Quantitative analysis of the density of trap states at the semiconductordielectric interface in organic field-effect transistors," Appl. Phys. Lett. 107(10), 103303 (2015).

${ }^{37}$ J. Levinson, F. R. Shepherd, P. R. Scanlon, W. D. Westwood, G. Este, and M. Rider, "Conductivity behavior in polycrystalline semiconductor thinfilm transistors," J. Appl. Phys. 53(2), 1193-1202 (1982); J. Park, Y. S. Jeong, K. S. Park, L. M. Do, J. H. Bae, J. S. Choi, C. Pearson, and M. Petty, "Subthreshold characteristics of pentacene field-effect transistors influenced by grain boundaries," J. Appl. Phys. 111(10), 104512 (2012).

${ }^{38}$ S. H. Jin, K. D. Jung, H. Shin, B. G. Park, and J. D. Lee, "Grain size effects on contact resistance of top-contact pentacene TFTs," Synth. Met. 156(2-4), 196-201 (2006).

${ }^{39}$ D. Hertel, H. Bässler, U. Scherf, and H. H. Hörhold, "Charge carrier transport in conjugated polymers," J. Chem. Phys. 110(18), 9214-9222 (1999).

${ }^{40} \mathrm{~S}$. Cherian, C. Donley, D. Mathine, L. LaRussa, W. Xia, and N. Armstrong, "Effects of field dependent mobility and contact barriers on liquid crystalline phthalocyanine organic transistors," J. Appl. Phys. 96(10), 5638-5643 (2004).

${ }^{41}$ W. T. Wondmagegn, N. T. Satyala, R. J. Pieper, M. A. Quevedo-Lopez, S. Gowrisanker, H. N. Alshareef, H. J. Stiegler, and B. E. Gnade, "Impact of semiconductor/metal interfaces on contact resistance and operating speed of organic thin film transistors," J. Comput. Electron. 10(1-2), 144-153 (2011)

${ }^{42}$ D. J. Gundlach, L. Zhou, J. A. Nichols, T. N. Jackson, P. V. Necliudov, and M. S. Shur, "An experimental study of contact effects in organic thin film transistors," J. Appl. Phys. 100(2), 024509 (2006).

${ }^{43}$ P. V. Necliudov, M. S. Shur, D. J. Gundlach, and T. N. Jackson, "Contact resistance extraction in pentacene thin film transistors," Solid-State Electron. 47, 259-262 (2003).

${ }^{44}$ C. Liu, Y. Xu, and Y. Y. Noh, "Contact engineering in organic field-effect transistors," Mater. Today 18(2), 79-96 (2015).

${ }^{45}$ U. Kraft, J. E. Anthony, E. Ripaud, M. A. Loth, E. Weber, and H. Klauk, "Low-voltage organic transistors based on tetraceno[2,3-b]mthiophene: Contact resistance and air stability," Chem. Mat. 27(3), 998-1004 (2015). 